\title{
Severe morbidity after antiretroviral (ART) initiation: active surveillance in HIV care programs, the leDEA West Africa collaboration
}

\author{
Yao Abo ${ }^{1,7^{*}}$, Marcel Zannou Djimon ${ }^{4,6}$, Eugène Messou ${ }^{5,3}$, Eric Balestre ${ }^{2,3}$, Martial Kouakou ${ }^{5}$, Jocelyn Akakpo ${ }^{4}$, \\ Carin Ahouada ${ }^{4}$, Nathalie de Rekeneire ${ }^{2,3}$, François Dabis ${ }^{2,3}$, Charlotte Lewdenn ${ }^{2,3}$, Albert Minga ${ }^{1,7}$ and on behalf of \\ the leDEA West Africa Collaboration
}

\begin{abstract}
Background: The causes of severe morbidity in health facilities implementing Antiretroviral Treatment (ART) programmes are poorly documented in sub-Saharan Africa. We aimed to describe severe morbidity among HIV-infected patients after ART initiation, based on data from an active surveillance system established within a network of specialized care facilities in West African cities.

Methods: Within the International epidemiological Database to Evaluate AIDS (leDEA) - West Africa collaboration, we conducted a prospective, multicenter data collection that involved two facilities in Abidjan, Côte d'Ivoire and one in Cotonou, Benin. Among HIV-infected adults receiving ART, events were recorded using a standardized form. A simple case-definition of severe morbidity (death, hospitalization, fever $>38^{\circ} 5 \mathrm{C}$, Karnofsky index $<70 \%$ ) was used at any patient contact point. Then a physician confirmed and classified the event as WHO stage 3 or 4 according to the WHO clinical classification or as degree 3 or 4 of the ANRS scale.

Results: From December 2009 to December 2011, 978 adults (71\% women, median age 39 years) presented with 1449 severe events. The main diagnoses were: non-AIDS-defining infections (33\%), AIDS-defining illnesses (33\%), suspected adverse drug reactions (7\%), other illnesses (4\%) and syndromic diagnoses (16\%). The most common specific diagnoses were: malaria (25\%), pneumonia (13\%) and tuberculosis (8\%). The diagnoses were reported as syndromic in one out of five events recorded during this study.

Conclusions: This study highlights the ongoing importance of conventional infectious diseases among severe morbid events occurring in patients on ART in ambulatory HIV care facilities in West Africa. Meanwhile, additional studies are needed due to the undiagnosed aspect of severe morbidity in substantial proportion.
\end{abstract}

Keywords: Antiretroviral therapy, Severe morbidity, Ambulatory HIV care facilities, West Africa

\section{Background}

In December 2010, an estimated 5,640,000 Human Immunodeficiency Virus (HIV)-infected people were receiving Antiretroviral Treatment (ART) in Sub-Saharan Africa (SSA), which represented a $20 \%$ increase in ART coverage compared to a year earlier [1]. Despite the rapid increase in availability of antiretroviral drugs in SSA since

\footnotetext{
* Correspondence: aysonabo@gmail.com

'Programme PAC-Cl, Centre Hospitalier Universitaire (CHU) de Treichville, 18 BP 1954 Abidjan 18, Côte d'Ivoire

${ }^{7}$ Centre Médical de Suivi des Donneurs de Sang (CMSDS), Centre National de Transfusion Sanguine, Abidjan, Côte d'Ivoire

Full list of author information is available at the end of the article
}

2004 [2], mortality and morbidity associated with HIV remain high among patients starting ART $[3,4]$. This high frequency of Acquired Immuno Deficiency Syndrome (AIDS)related morbidity is due to late diagnosis of HIV infection and consequently leading to a late initiation of treatment [5].

According to the available literature, severe morbidity is common during the first months after ART initiation and remains high thereafter. Specifically, this severe morbidity is characterized by a high incidence of invasive bacterial diseases and tuberculosis [6,7]. Among SSA hospitalized HIV-positive patients, the most frequent causes of hospitalization are AIDS-defining conditions, tuberculosis 
and bacterial infections [8-10]. A high incidence of serious morbidity was recorded among HIV-infected adults followed up in routine conditions in SSA ambulatory care centers $[11,12]$. In addition to these infectious diseases, antiretroviral drugs expose patients to severe adverse events [13-15]. With the increase of life expectancy as the result of ART initiation, HIV-infected patients are more likely to present with non infectious diseases [16].

Available data on morbidity mainly come from research settings with advanced diagnostic capacities [3,4,7]. In SSA, causes of severe morbidity and mortality after ART initiation are poorly documented in health facilities implementing ART under routine circumstances, as data collection is still a challenge in those settings [17].

To fill this lack of data, the International epidemiological Database to Evaluate AIDS (IeDEA) was implemented in the West African region. It was launched to collect and harmonize data from multiple HIV/AIDS cohorts from industrialized and resource-limited countries. The IeDEA collaboration aims to address research questions in the field of HIV/AIDS care and treatment, especially in low-income countries, where most ART scale-up take place. The IeDEA West Africa is a prospective and observational multicohort collaboration established in 2006. It includes data from 8 countries with 15 centers for adult-patients infected with HIV on ART in Benin, Burkina Faso, Côte d'Ivoire, Guinea-Bissau, Mali, Nigeria, Senegal and Togo [18,19].

This collaboration could help address questions that have been poorly documented in this context, such as morbidity. Because of rapid changes in therapeutic strategies, a minimal morbidity surveillance in HIV care facilities of SSA is required [20-22].

The objective of our study was, to describe severe morbidity occurring among HIV-infected adult patients, receiving ART based on surveillance data collected prospectively under routine circumstances in HIV/AIDS care facilities in SSA.

\section{Methods}

\section{Study design}

The current study was conducted between December 2009 and December 2011, within the IeDEA network in West Africa [17,18] (see Additional file 1). For the purpose of this project, we conducted a prospective, multicenter ancillary study that involved three health care facilities. Among them, two were in Abidjan, Côte d'Ivoire: the Medical Center for the Monitoring of Blood Donors (CMSDS) and the Centre for Care, Research and Training (Aconda-CePReF). The other one was in Cotonou, Benin: the Outpatient Care Center of the National University Hospital (CTA/CNHU). All these three facilities are ambulatory HIV care centers that participated on a voluntary basis.

\section{Study population}

The study population consisted of HIV-infected individuals, aged 18 and over, receiving ART in one of the three participating facilities. Those centers were chosen on the basis of a convenience sampling among the ambulatory care centers participating in the West Africa IeDEA collaboration.

\section{Definition of severe morbidity}

We defined a severe event as the occurrence of one of the following events: death, hospitalization, fever (temperature above $385^{\circ} \mathrm{C}$ ) or Karnofsky index $<70 \%$ in any patient on ART. Any patient with at least one of these signs was included in this study. The centers involved in this study were exclusively outpatient clinics. Therefore, deaths were reported by the patients' siblings during telephone reminders made by the social workers. A standardized data collection form was used to record these events.

Physicians and other Health care workers (HCWs) (data collection technicians, social workers, nurses, pharmacy aides) from participating centers were trained to identify severe morbidity based on the four signs included in the definition. HCWs other than physicians, initiate a form by filling in the survey form with the sign(s) of severe morbidity experienced by the patients and their identification numbers. Physicians were responsible for completing the forms with clinical examination results. In case the physician noticed signs of severe morbidity by himself, he could initiate and fill the entire record.

Once the form was completed by the physician, additional testing might be requested to confirm the diagnosis. The final diagnosis was established by the physician in charge of the patient. This final diagnosis, either accurate or syndromic was chosen for the study. First, the diagnosis was accurate when it led to a specific disease and was based on additional testing. Then, the diagnosis was syndromic when it was mentioned as a sign and was not based on further investigation. Each diagnosis was classified by the physician according to the World Health Organization (WHO) clinical stage classification [23] and/or to the the Agence Nationale de Recherche sur le Sida et les hépatites Virales (ANRS) [24].

A physician was appointed at each center for the supervision of the study. $\mathrm{He} / \mathrm{she}$ received all the forms daily, checked data completeness and the accuracy.

\section{Data collection}

First, the physician in charge of the study at each center controlled the quality of the filled out survey forms. Next, documented severe events were subsequently coded according to a validated list of codes of the International Classification of Diseases, tenth revision (ICD10) [25]. Then, the coded events were entered into a computer database and transferred from each health 
facility to the central database at the IeDEA West Africa coordination center.

\section{Main diagnostic procedures}

Ambulatory care centers for HIV-infected patients need to provide them with, both routine follow-up laboratory examination and additional laboratory testing. The Table 1 gives a summary of the available tests.

\section{Description of study findings}

For each severe event, we described the main diagnosis, among the one, two or three diagnoses reported by the physician. If a patient had several diagnoses, we determined one main diagnosis by using the following priority order: first, WHO stage 4 opportunistic disease, second, WHO stage 3 opportunistic disease, third, other infection, fourth, other cancer, Fifth, WHO stage 4 cachexia, sixth, other disease and seventh, non specific event including syndromic diagnosis and non specific WHO stage 3 events (weight loss $>10 \%$, chronic diarrhoea, persistent fever). We also described the total number of diagnoses and their percentage separately, using the total number of events as denominator.

\section{Statistical methods}

Patient characteristics were described using the median and interquartile range (IQR) of continuous variables and the frequency distribution of categorical variables.

\section{Ethical approval}

The IeDEA West Africa Collaboration obtained authorization from the Ethics committee "Comité de Protection des Personnes Sud-Ouest et Outre-mer III" in Bordeaux, France. Moreover, each site obtained authorization from its National Ethics committee: The
"Comité National d'Ethique et de la Recherche (CNER)", in Côte d'Ivoire and the "Comité National d'Ethique pour la Recherche en Santé (CNERS)", in Benin. The physicians in charge of patients at each site obtained written informed consent from the patients included in this study.

\section{Results}

Between December 2009 and December 2011, 978 HIVinfected adults followed up in three facilities of the IeDEA West Africa collaboration and presenting at least with one severe event were included in this study. Patients were mainly female (71\%), with a median age of 39 years (IQR: $33-45)$. The cumulative follow-up period from ART initiation to the first severe event was 3465 person-years (PY) with a median of 23.1 months [IQR (3.4 to 54.7)] (Table 2). Among the 978 patients, 570 $(58.3 \%)$ were followed up at Aconda-CePReF, 210 (21.5\%) at CTA/CNHU and $198(20.2 \%)$ at CMSDS. In these 978 patients, 1449 events occurred: 955 (65.9\%) at Aconda-CePReF, 255 (17.6\%) at CTA/CNHU and 239 (16.5\%) at CMSDS (Table 2).

The main diagnoses reported among these 1449 severe events were: non-AIDS-defining infection (32.6\%), AIDS-defining illness (33.2\%) with $23.3 \%$ in WHO stage 3 and $9.5 \%$ in WHO stage 4 , suspected adverse drug reactions (7.1\%), and finally non-infectious diseases and non-AIDS-defining illnesses (4.8\%). In $16 \%$ of the cases, the diagnosis remained syndromic (Table 3). In this group, anemia (32\%), fever (20\%) and digestive disorders (13\%) were the most common syndromic diagnoses. Detailed diagnoses reported for these severe events are presented in Table 4. Malaria (25\%), pneumonia (13.4\%) and tuberculosis $(7.7 \%)$ were the most common diagnoses. During the study period, 180 patients (13\%) died

Table 1 Main diagnostic procedures in the three participating centers, leDEA West Africa, December 2009 to December 2011

\begin{tabular}{|c|c|c|c|}
\hline Centers & CMSDS & Aconda-CePReF & CTA/CNHU \\
\hline \multicolumn{4}{|l|}{ Diagnostic procedures } \\
\hline \multicolumn{4}{|l|}{ Monitoring routine tests } \\
\hline Full blood count & * & * & * \\
\hline CD4 lymphocytes & * & * & * \\
\hline Plasma urea and creatinine & * & * & * \\
\hline Glycemia & * & * & * \\
\hline \multicolumn{4}{|c|}{ Additional tests for diagnosis of diseases } \\
\hline Thick film & * & ** & $* * *$ \\
\hline Sputum examination & $* * *$ & ** & $* * *$ \\
\hline Radiography & $* * *$ & **: & **: \\
\hline Computed Tomography & $* * *$ & ** & $* * *$ \\
\hline
\end{tabular}

*Available at the center and free of charge.

**Available on site but not free of charge.

***Not available at the center. 
Table 2 Characteristics at initiation of antiretroviral treatment (ART) and during follow-up (last visit) of HIV-infected adults in the three participating centers, leDEA West Africa, December 2009 to December 2011

\begin{tabular}{|c|c|c|c|c|c|c|c|c|}
\hline & \multirow{2}{*}{\multicolumn{2}{|c|}{$\begin{array}{l}\text { Total } \\
\mathrm{N}=978\end{array}$}} & \multirow{2}{*}{\multicolumn{2}{|c|}{$\begin{array}{l}\text { Aconda-CePReF } \\
\mathrm{n}=570\end{array}$}} & \multirow{2}{*}{\multicolumn{2}{|c|}{$\begin{array}{l}\text { CMSDS } \\
n=198\end{array}$}} & \multirow{2}{*}{\multicolumn{2}{|c|}{$\begin{array}{l}\text { CTA/CNHU } \\
n=210\end{array}$}} \\
\hline & & & & & & & & \\
\hline & \multirow[b]{2}{*}{692} & \multirow[b]{2}{*}{ (71) } & \multirow[b]{2}{*}{420} & \multirow[b]{2}{*}{$(74)$} & \multirow[b]{2}{*}{140} & \multirow[b]{2}{*}{ (71) } & \multirow[b]{2}{*}{119} & \multirow[b]{2}{*}{$(57)$} \\
\hline $\begin{array}{l}\text { Characteristics } \\
\text { At ART initiation } \\
\text { Sex, woman, n (\%) }\end{array}$ & & & & & & & & \\
\hline Age (years), median (IQR) & 39 & $(33-45)$ & 36 & $(31-44)$ & 35 & $(31-41)$ & \multirow{2}{*}{21.0} & $(31-42)$ \\
\hline \multirow{2}{*}{$\begin{array}{l}\text { BMI }\left(\mathrm{Kg} / \mathrm{m}^{2}\right) \text {, median (IQR) } \\
\text { CD4 }\left(/ \mathrm{mm}^{3}\right) \text {, number, median (IQR) }\end{array}$} & 20.1 & $(17.9-22.7)$ & 19.7 & $(17.6-22.2)$ & 20.8 & $(18.7-23.7)$ & & $(18.8-24.6)$ \\
\hline & 137 & $(59-239)$ & 136 & $(61-249)$ & 157 & $(60-242)$ & 108 & $(47-180)$ \\
\hline \multicolumn{9}{|l|}{ Antiretroviral treatment, $\mathrm{n}(\%)$} \\
\hline $2 N R T I S+1 N N R T I S$ & 678 & $(69.3)$ & 381 & $(66.8)$ & 135 & $(68,2)$ & 162 & $(77,1)$ \\
\hline $2 \mathrm{NRTIS}+1 \mathrm{PI}$ & 87 & (9) & 48 & (8) & 26 & (13) & 13 & (6) \\
\hline Other & 213 & $(22)$ & 141 & $(25)$ & 37 & (19) & 35 & $(17)$ \\
\hline \multicolumn{9}{|l|}{ Follow-up data* } \\
\hline Total follow-up (months), median (IQR) & 34.9 & $(16.3-67.1)$ & 35.5 & $(14.6-66.2)$ & 35.0 & $(18.2-54.1)$ & 33.5 & $(16.9-76.6)$ \\
\hline Follow-up until event (months), median (IQR) ((I/((IQR) & 23.1 & $(3.4-54.6)$ & 24.6 & $(2.6-55.5)$ & 18.7 & $(3.5-43.1)$ & 23.2 & $(5.8-66.2)$ \\
\hline $\mathrm{CD} 4$ cell/mm³ median (IQR) & 269 & $(103-467)$ & 267 & $(102-453)$ & 289 & $(124-517)$ & 237 & $(73-468)$ \\
\hline \multicolumn{9}{|l|}{ WHO stage, n (\%) } \\
\hline Stage 1 or 2 & 167 & $(17.1)$ & 29 & (5) & 119 & $(60.2)$ & 19 & (9) \\
\hline Stage 3 & 242 & $(24.7)$ & 128 & (22) & 48 & $(24.2)$ & 66 & (31) \\
\hline Stage 4 & 80 & $(8.2)$ & 41 & (7) & 27 & (13.6) & 12 & (6) \\
\hline
\end{tabular}

$\mathrm{QQR}=$ Interquartile Range.

$\mathrm{BMI}=$ Body Mass Index

WHO $=$ World Health Organisation.

ART $=$ Antiretroviral Treatment.

Aconda-CePReF = Centre for Care, Research and Training.

CMSDS = Medical Centre for Monitoring Blood Donors.

CTA/CNHU = Outpatient Treatment Centre of the National University Hospital.

NNRTIs = Non Nucleoside Reverse Transcriptase Inhibitors.

$\mathrm{Pls}=$ Protease Inhibitors.

$\mathrm{AZT}=$ Zidovudine.

D4T = Stavudine.

3TC = Lamivudine

*: close to the event: At the time of the morbid event.

Table 3 Main ${ }^{*}$ diagnoses of the 1449 events reported in HIV-infected adults receiving antiretroviral treatment, leDEA West Africa, December 2009 to December 2011

\begin{tabular}{|c|c|c|c|c|c|c|c|c|}
\hline \multirow{2}{*}{$\begin{array}{l}\text { Diagnosis classification, } \\
\text { number }(\%)\end{array}$} & \multicolumn{2}{|c|}{ Total 1449} & \multicolumn{2}{|c|}{ Aconda-CePReF } & \multicolumn{2}{|c|}{ CMSDS } & \multicolumn{2}{|c|}{ CTA/CNHU } \\
\hline & \multicolumn{2}{|c|}{$\mathrm{N}=1449$} & \multicolumn{2}{|c|}{$\mathrm{n}=955$} & \multicolumn{2}{|c|}{$\mathrm{n}=\mathbf{2 3 9}$} & \multicolumn{2}{|c|}{$n=255$} \\
\hline \multicolumn{9}{|l|}{ AIDS-defining events } \\
\hline WHO stage 4 events & 137 & $(9.5)$ & 68 & $(7.1)$ & 31 & (13) & 38 & $(14.9)$ \\
\hline WHO stage 3 events & 338 & $(23.3)$ & 214 & $(22.4)$ & 24 & (10) & 100 & $(39.2)$ \\
\hline WHO stage 2 events & 6 & $(0.4)$ & 5 & $(0.5)$ & 0 & (0) & 1 & $(0,4)$ \\
\hline \multicolumn{9}{|l|}{ Non-AIDS-defining events } \\
\hline Non AIDS classifying infections & 472 & $(32.6)$ & 379 & $(39.7)$ & 51 & $(21.3)$ & 42 & $(16.5)$ \\
\hline Side effects** & 104 & $(7.2)$ & 34 & (3.6) & 32 & $(13.4)$ & 38 & $(14.9)$ \\
\hline Other diagnosed diseases & 63 & $(4.3)$ & 35 & $(3.7)$ & 12 & (5) & 16 & $(6.3)$ \\
\hline Syndromic diagnoses ${ }^{* * *}$ & 228 & $(16.0)$ & 160 & $(17.0)$ & 55 & (23.0) & 13 & $(5.1))$ \\
\hline Death & 101 & $(7.0)$ & 60 & $(6.0)$ & 34 & (14.2) & 7 & (3.0) \\
\hline
\end{tabular}

*: one diagnosis per event.

**: (anemia $=36$, peripheral neuropathy $=33$, toxiderma $=21$, neutropenia $=5$, lipodystrophy $=4$, acute delusional psychosis $=2$, hyperlactatemia $=2$, hepatitis $=1$ )

*** $[$ anemia $=72$, fever $=46$, general signs (Asthenia, anorexia $=37$ ), digestive signs (diarrhea, vomiting) $=30$, other signs $=43]$. 
Table 4 Syndromic and definitive diagnoses ${ }^{\gamma}$ according to WHO stages and ANRS degrees of severity, in HIV-infected adults receiving antiretroviral treatment, leDEA West Africa, December 2009 to December 2011

\begin{tabular}{|c|c|c|c|c|c|c|c|c|}
\hline \multirow[t]{2}{*}{ Diagnoses, number } & \multirow{2}{*}{$\begin{array}{l}\text { Total } \\
\mathrm{N}=1675\end{array}$} & \multirow[b]{2}{*}{$(\%)$} & \multicolumn{2}{|c|}{ WHO classification } & \multicolumn{2}{|c|}{ ANRS degrees of severity } & \multirow[t]{2}{*}{ Hospitalisation* } & \multirow[t]{2}{*}{ Death** } \\
\hline & & & Stage 3 & Stage 4 & Degree 3 & Degree 4 & & \\
\hline \multicolumn{9}{|l|}{ Infectious events } \\
\hline \multicolumn{9}{|l|}{ Parasitic events } \\
\hline Malaria & 359 & $(24.8)$ & & & 99 & 12 & 127 & \\
\hline Cerebral toxoplasmosis & 24 & $(1.7)$ & 0 & 24 & & & 15 & 3 \\
\hline Other parasitic events ${ }^{\ddagger}$ & 9 & $(0.6)$ & & 3 & 1 & & 2 & \\
\hline \multicolumn{9}{|l|}{ Bacterial events } \\
\hline Pneumonia & 194 & $(13.4)$ & 194 & & & & 79 & 2 \\
\hline Tuberculosis & 111 & $(7.7)$ & 45 & 66 & & & 43 & 4 \\
\hline ENT infection & 26 & $(1.8)$ & & & 2 & & 3 & \\
\hline Severe bacterial infection & 17 & $(1.2)$ & 17 & & & & 7 & 1 \\
\hline Other events ${ }^{\beta}$ & 12 & $(0.8)$ & & & 2 & 2 & 3 & \\
\hline \multicolumn{9}{|l|}{ Mycotic events } \\
\hline Oral candidiasis & 138 & $(9.5)$ & 133 & & & & 8 & \\
\hline Other mycoses ${ }^{£}$ & 25 & $(1.7)$ & & 11 & & & 1 & \\
\hline Infectious diarrhoea & 121 & $(8.4)$ & & & 45 & 12 & 75 & \\
\hline Skin infections & 16 & $(1.1)$ & & & 1 & & 5 & \\
\hline Viral infections ${ }^{\pi}$ & 35 & $(2.4)$ & & 25 & 1 & & 15 & 1 \\
\hline Other infectious events ${ }^{a}$ & 27 & $(1,9)$ & & & 5 & 4 & 10 & \\
\hline \multicolumn{9}{|l|}{ Non infectious diagnosis } \\
\hline Peripheral neuropathy*** & 52 & (3.6) & & & 39 & 5 & 5 & \\
\hline Toxiderma & 19 & $(1.3)$ & & & 6 & 7 & 11 & \\
\hline Tumors & 17 & $(1.2)$ & & 11 & & 1 & 9 & \\
\hline Other non infectious diagnoses ${ }^{\psi}$ & 46 & $(3.2)$ & & & 8 & 17 & 13 & 1 \\
\hline \multicolumn{9}{|l|}{ Non specific events } \\
\hline Anemia $^{\dagger}$ & 164 & $(11.3)$ & & & 57 & 82 & 84 & 3 \\
\hline Fever & 49 & $(3.4)$ & & 4 & 9 & 4 & 10 & 1 \\
\hline Diarrhoea & 25 & $(1.7)$ & & 5 & 11 & 1 & 18 & 2 \\
\hline Other general signs ${ }^{\ominus}$ & 57 & (3.9) & & & 23 & 16 & 41 & 2 \\
\hline Other non specific ${ }^{\phi}$ & 31 & $(2.1)$ & & & 7 & 5 & 32 & 3 \\
\hline Death & 101 & & & & & & & \\
\hline
\end{tabular}

ENT $=$ Ear Nose Throat.

y Several diagnoses for a same event.

*Number of events with at least one day in day care.

* Number of death occurring after the event.

*** including 37 neuropathies secondary to ART initiation.

(\%) Percentage calculated based on the number of events.

${ }^{+}$including 54 anaemia secondary to a treatment.

${ }^{\ddagger} 6$ ameibiasis, 2 pneumocystoses, 1 microsporidia.

${ }^{\beta} 9$ urinary infections, 2 appendicites, 1 cholecystitis.

⿷ 11 vaginal candidosis, 10 oesophagal candidosis, 3 digestive candidosis, 1 cryptococcal.

"21 HIV-related cachexia syndrome, 8 herpes zoster, 4 HIV-related encephalopathies, 2 herpes.

Tumors: 9 kaposi, 4 benign tumors, 2 unkown evolutive tumors, 1 cervical cancer, 1 Non-Hodgkin malignant Lymphoma.

${ }^{\psi}$ Cardio-vascular ( 6 arterial hypertension, 4 peripheral veins, 2 stroke), Renal ( 6 nephropathy, 6 renal failure), metabolic (5 abnormal fat distribution, 1 lactic

acidosis, 1 diabetes), Genito-obstetric (two abortions, two other), Gastrointestinal (3 gastric or duodenal ulcers, 1 chronic pancreatitis, 7 other.

a genital infections, 6 osteoarticular infections, 6 broncho-pneumopathy, 5 meningitis, 2 stomatitis, 1 hepatitis.

${ }^{\theta} 19$ asthenia, 21 dehydration, 17 under-nutrition.

$\Phi_{1}$ digestive disorders, 6 hemiplegia/tetraplegia, 6 psychiatric signs, 5 neutropenia, 2 liver signs, 11 other signs. 
and among $80 \%$ of them, the cause of death could not be determined with precision (Table 4). The distribution of the 1449 severe events according to the circumstances of their identification was: regular or day hospitalization (41.5\%), fever (29.8\%), death (8.6\%), Karnofsky index < 70\% (4.5\%), other reasons $(16 \%)$.

\section{Discussion}

A prospective data collection system for severe morbidity was performed in three ambulatory HIV care facilities in West Africa. We collected standardized data from several patient contact points in each facility. NonAIDS-defining infectious diseases and AIDS-defining diseases were the most frequent groups of morbid events observed in one-third of the patients. The most common specific diagnoses were malaria, pneumonia and tuberculosis. The diagnosis was defined as syndromic in one out of five cases.

This study showed the feasibility of routine collection of severe morbidity data among patients on ART based on: (i) the definition of reported signs of severe morbidity adapted to all staff and all care facilities and (ii) the definition and use of a simple data form. This organization involving all staff (data collection technicians, social workers, paramedics and physicians) and all services (reception desk, pharmacy, nursing, medical consultation, day care) had the advantage of being reproducible and affordable due to its integration within the existing system.

Regarding the WHO clinical stage 3 or 4 events, our results are consistent with those of previous studies $[3,4]$ and could be explained by the late diagnosis of HIV infection or delayed ART initiation in this resourcelimited setting [21]. Despite recent and repeated changes in the criteria for ART initiation in resource-limited countries $[20,21,26]$, these changes were far from being fully implemented at the time of the study in most of these countries. Previous studies conducted in the context of the 2006 WHO criteria for ART initiation, have shown that patients started ART late with low CD4 [27]. This delay in ART initiation could explain the persistence of AIDS-defining illnesses after ART initiation. Enhanced and multiple opportunities of HIV testing are necessary to change this pattern of events.

The World Health Organization recently recommended to supply centers with rapid diagnostic tests for malaria [28]. This decision was not implemented in the participating centers during the study period. Indeed, among the three participating centers, only the CMSDS performed routine thick smears in suspected malaria cases at no cost to patients. Despite the high endemicity of malaria in the study area and the consistency of our results with those of some authors [29], we discussed the hypothesis of a possible overestimation of this diagnosis as confirmed by other studies [30,31]. Indeed one of the signs of serious illness was fever which is also one of the main signs of malaria. Some patients were not able to benefit from this testing due to financial constraints. Some of them could have been wrongly classified as malaria cases, thus overestimating the number of cases.

We also found that pneumonia as well as tuberculosis were the most common frequent AIDS-defining event while on ART. This result was also mentioned in previous studies in SSA [32,33], confirming the endemicity of these lung diseases in the study area at the current level of ART coverage [34,35].

Improvements have been made in the health care system in Africa more particularly in SSA. However, progress remains to be made. Among the challenges health care services deal with in Africa, underdeveloped infrastructures and weak healthcare systems are the most predominant [36]. As regards to HIV management, over $75 \%$ of expenses related to HIV care are faced by patients, and more than $50 \%$ of these expenses are allocated to the diagnosis and treatment of opportunistic infections) [37-39]. One of the consequences of these weaknesses is the difficulty to investigate the diagnoses of morbid events observed in patients. Therefore, we recommend strengthening the capacity of laboratories in HIV care facilities, by providing them with general laboratory testing in addition to efforts made to have antiretroviral drugs and specific HIV tests available in outpatient centers. Some of the events in this study were reported as syndromic diagnoses. Given the seriousness of some of these signs (fever, diarrhea), providing outpatient facilities with rapid diagnostic tests for malaria or conventional X-rays, should elucidate some of the diagnoses. Indeed, these general laboratory tests are part of the essential components of a basic package of HIV care and treatment [40,41]. Free access to those general laboratory testing in addition to the current free access to ART and specific HIV testing $[42,43]$ will improve their accessibility.

The main strengths of this study are its prospective and multicenter design. First, a prospective study because for each patient's symptom, all the information were documented according to a standardized procedure that minimized the risk of information bias. Then, a multicenter study, as it involved a large and unselected population of HIV-infected patients in care in the West African region. The use of a standardized data collection form contributed to ensure accuracy in data collection and limitation of variations within and among facilities. The involvement of almost all health care professionals at all levels and from all services was also instrumental in collecting the maximum number of events occurring during the study period.

Our study also had some limitations. The severity of a morbid event can be a reason for treatment discontinuation in HIV care centers. Thus, the methodology of our 
study, which consisted in capturing information about patients with severe morbidities at the three study facilities, is a limitation. Some patients suffering from severe events with restricted mobility and those with severe events lacking financial resources to travel to the facilities may have been excluded from this study, therefore leading to a selection bias. Another limitation is that specific signs of interest were identified a priori before taking the event into account. Some events may have been severe but without any of these predefined signs, thus leading to their inappropriate exclusion. In addition, due to the lack of resources, some patients might have restricted access to definitive diagnoses. Besides, some hospitalizations might have not been reported to us. All these biases may have contributed to an underestimation of severe morbidity.

In order to carry out an efficient intervention and deliver a more adequate service in a context of general weak health systems, further studies with access to diagnostic tests are needed to confirm the patterns observed in terms of syndromic diagnoses. Such studies could contribute to promote funding and the routine use of general laboratory tests to diagnose morbid events in resource-limited settings.

\section{Conclusion}

Standardized and routine collection of severe morbidity data is possible in HIV/AIDS care facilities under routine circumstances. This study highlights the ongoing importance of common infectious diseases among severe morbid events occurring in patients on ART in national HIV care facilities in West Africa. Meanwhile, additional studies are needed due to the undiagnosed aspect of severe morbidity in substantial proportion.

\section{Additional file}

Additional file 1: The leDEA West Africa Collaboration Study Group.

\section{Competing interests}

The authors declare that they have no competing interests.

\section{Authors' contributions}

All the authors designed and implemented the study; they had full access to raw data. LC and BE performed all analyses. YA wrote the manuscript. All the authors helped draft the manuscript and read and approved the final manuscript.

\section{Acknowledgements}

We thank the local teams at CMSDS, Aconda-CePReF and CTA/CNHU involved in this study. We gratefully acknowledge the invaluable contributions of all patients from these various facilities.

\section{Funding}

The National Cancer Institute (NCl), the Eunice Kennedy Shriver National Institute of Child Health \& Human Development (NICHD) and the National Institute of Allergy and Infectious Diseases (NIAID) of the U.S. National Institutes of Health (NIH), as part of the International Epidemiologic Databases to Evaluate AIDS (leDEA) under Award Number U01AI069919. The content is solely the responsibility of the authors and does not necessarily represent the official views of the National Institutes of Health.

\section{Author details}

'Programme PAC-Cl, Centre Hospitalier Universitaire (CHU) de Treichville, 18 BP 1954 Abidjan 18, Côte d'Ivoire. ${ }^{2}$ INSERM, Centre INSERM

U897-Epidémiologie-Biostatistique, Bordeaux, France. ${ }^{3}$ University Bordeaux, ISPED, Bordeaux, France. ${ }^{4}$ Centre de Traitement Ambulatoire (CTA), Centre National Hospitalier Universitaire (CNHU), Cotonou, Benin. ${ }^{5}$ Centre de Prise en charge de Recherche et de Formation (Aconda-CePReF), Abidjan, Côte d'Ivoire. ${ }^{6}$ Université d'Abomey-Calavi, Cotonou, Bénin. ${ }^{7}$ Centre Médical de Suivi des Donneurs de Sang (CMSDS), Centre National de Transfusion Sanguine, Abidjan, Côte d'Ivoire.

Received: 31 July 2014 Accepted: 18 March 2015

Published online: 09 April 2015

\section{References}

1. UNAIDS/WHO. Global HIV/AIDS response: Epidemic update and health sector progress towards Universal Access; Progress report 2011. Geneva: UNAIDS/WHO; 2011. Available at: http://whqlibdoc.who.int/publications/ 2011/9789241502986_eng.pdf. Accessed May, 4, 2012.

2. World Health Organization. Towards Universal access: scaling up priority HIV/AIDS interventions in the health sector. Progress report 2008. Geneva, Switzerland: World Health Organization; 2009. Available at :http://www.who. int/hiv/pub/tuapr_2009_en.pdf. Accessed May, 5, 2009.

3. Moh R, Danel C, Messou E, Ouassa T, Gabillard D, Anzian A, et al. Incidence and determinants of mortality and morbidity following early antiretroviral therapy initiation in HIV-infected adults in West Africa. AIDS. 2007;21(18):2483-91.

4. Seyler C, Messou E, Gabillard D, Inwoley A, Alioum A, Anglaret X. Morbidity before and after HAART initiation in Sub-Saharan African HIV-infected adults: a recurrent event analysis. AIDS Res Hum Retroviruses. 2007;23(11):1338-47.

5. Delphine G, Charlotte L, Ibra N, Raoul M, Olivier S, Besigin T-G, et al. Mortality, AIDS-morbidity, and loss to follow-up by current CD4 cell count among HIV-1-infected adults receiving antiretroviral therapy in Africa and Asia: Data From the ANRS 12222 Collaboration. J Acquir Immune Defic Syndr. 2013;62:555-61.

6. Lawn SD, Harries AD, Anglaret X, Myer L, Wood R. Early mortality among adults accessing antiretroviral treatment programmes in sub-Saharan Africa. AIDS. 2008;22(15):1897-908

7. Losina E, Yazdanpanah Y, Deuffic-Burban S, Wang B, Wolf LL, Messou E, et al. The independent effect of highly active antiretroviral therapy on severe opportunistic disease incidence and mortality in HIV-infected adults in Cote d'Ivoire. Antivir Ther. 2007;12(4):543-51.

8. Lewden C, Drabo YJ, Zannou DM, Maiga MY, Minta DK, Sow PS, et al. Disease patterns and causes of death of hospitalized HIV-positive adults in West Africa: a multicountry survey in the antiretroviral treatment era. J Int AIDS Soc. 2014;17:18797.

9. Namutebi AM, Kamya MR, Byakika-Kibwika P. Causes and outcome of hospitalization among HIV-infected adults receiving antiretroviral therapy in Mulago hospital, Uganda. Afr Health Sci. 2013;13(4):977-85.

10. Ogoina D, Obiako RO, Muktar HM, Adeiza M, Babadoko A, Hassan A, et al. Morbidity and mortality patterns of hospitalised adult HIV/AIDS patients in the Era of highly active antiretroviral therapy: a 4-year retrospective review from Zaria, Northern Nigeria. AIDS Res Treat. 2012;2012:940580.

11. Abo $Y$, Minga $A$, Menan $H$, Danel $C$, Ouassa $T$, Dohoun $L$, et al. Incidence of serious morbidity in HIV-infected adults on antiretroviral therapy in a West African care centre, 2003-2008. BMC Infect Dis. 2013;13:607.

12. Moon TD, Silva WP, Buene M, Morais L, Valverde E, Vermund SH, et al. Bacteremia as a cause of fever in ambulatory, HIV-infected Mozambican adults: results and policy implications from a prospective observational study. PLoS One. 2013;8(12):e83591.

13. Coffie PA, Tonwe-Gold B, Tanon AK, Amani-Bosse C, Bedikou G, Abrams EJ, et al. Incidence and risk factors of severe adverse events with nevirapine-based antiretroviral therapy in HIV-infected women. MTCT-Plus program, Abidjan, Cote d'Ivoire. BMC Infect Dis. 2010;10:188.

14. Minga A, Lewden C, Dohoun L, Abo Y, Emieme A, Coulibaly A, et al. Short communication: Severe symptomatic hyperlactatemia among HIV type 1-infected adults on antiretroviral therapy in Cote d'Ivoire. AIDS Res Hum Retroviruses. 2010;26(9):991-5. 
15. Moh R, Danel C, Sorho S, Sauvageot D, Anzian A, Minga A, et al. Haematological changes in adults receiving a zidovudine-containing HAART regimen in combination with cotrimoxazole in Cote d'Ivoire. Antivir Ther. 2005;10(5):615-24.

16. Ali MK, Magee MJ, Dave JA, Ofotokun I, Tungsiripat M, Jones TK, et al. HIV and metabolic, body, and bone disorders: what we know from low- and middle-income countries. J Acquir Immune Defic Syndr. 2014;67 Suppl 1: S27-39.

17. Ekouevi DK, Karcher S, Coffie PA. Strengthening health systems through HIV monitoring and evaluation in Sub-Saharan Africa. Curr Opin HIV AIDS. 2011;6(4):245-50.

18. Balestre E, Eholie SP, Lokossue A, Sow PS, Charurat M, Minga A, et al. Effect of age on immunological response in the first year of antiretroviral therapy in HIV-1-infected adults in West Africa. AIDS. 2012;26(8):951-7.

19. Ekouevi DK, Balestre E, Ba-Gomis FO, Eholie SP, Maiga M, Amani-Bosse C, et al. Low retention of HIV-infected patients on antiretroviral therapy in 11 clinical centres in West Africa. Trop Med Int Health. 2010;15 Suppl 1:34-42.

20. World Health Organization. Scaling up Antiretroviral therapy in resource-limited Settings: treatment Guidelines for a public heal thapproch (Revision 2003). Geneva; 2003. Available at: http://www.who.int/hiv/pub/prev_care/en/ arvrevision2003en.pdf. Accessed October, 11, 2012.

21. World Health Organization. Antiretroviral Therapy For Hiv Infection In Adultsand Adolescents: Recommendationsfor a public health approach(2006 revision); 2006. Available at: http://www.who.int/hiv/pub/guidelines/artadultguidelines.pdf. Accessed January, 23, 2012.

22. World Health Organization. Antiretroviral therapy for HIV infection in adults and adolescents:Recommendations for a public health approach (2010 version). 2010. Available at: http://whqlibdoc.who.int/publications/2010/ 9789241599764_eng.pdf?ua=1596657_eng.pdf. Accessed January, 23, 2012

23. World Health Organization. Interim who clinical staging of HIV/AIDS and hiv/aids case definitions for surveillance. 2005. Available at: http://www.who. int/hiv/pub/guidelines/clinicalstaging.pdf. Accessed March, 1st, 2011.

24. Tonéatti C, Bouxin-Metro A, Dormont J. Echelle ANRS de cotation de la gravité des événements indésirables graves chez l'adulte. Version n6 du 9 septembre 2003 [Report on line]. Paris: ANRS; 2003. Available at: http:// www.anrs.fr/Rubriques-transversales/Outils-pour-la-recherche/Pays-endeveloppement/Preparer-la-recherche/Declaration-des-evenements.

25. World Health Organization. International Statistical Classification of Diseases and Related Health Problems (ICD10), 10th revision, Volume 2 instruction manual, 2010 edition. Geneva: World Health Organization; 2010. Available at: http://www. who.int/classifications/icd/ICD10Volume2_en_2010.pdf. Accessed July, 25, 2012.

26. World Health Organization. Consolidated guidelines on the use of antiretroviral drugs for treating and preventing HIV infection. Recommendations for a public health approach; 2013. Available at: http://www.who.int/hiv/pub/guidelines/ arv2013/en/index.html. Accessed July, 18, 2013.

27. The leDEA and ART cohort collaborations. Immunodeficiency at the start of combination antiretroviral therapy in low-, middle- and high-income countries. J Acquir Immune Defic Syndr. 2014;65(1):e8-16.

28. World Health Organization. WHO Global Malaria Program. World Malaria report 2011. Geneva; 2011. Available at: http://www.who.int/malaria/ publications/atoz/9789241564403/en/index.html. Accessd August, 1st, 2013.

29. Campbell JD, Moore D, Degerman R, Kaharuza F, Were W, Muramuzi E, et al. HIV-infected ugandan adults taking antiretroviral therapy with CD4 counts $>200$ cells/muL who discontinue cotrimoxazole prophylaxis have increased risk of malaria and diarrhea. Clin Infect Dis. 2012;54(8):1204-11.

30. Brentlinger $P E$, Silva WP, Buene $M$, Morais $L$, Valverde $E$, Vermund $S H$, et al. Management of fever in ambulatory HIV-infected adults in resource-limited settings: prospective observational evaluation of a New Mozambican guideline. J Acquir Immune Defic Syndr. 2014;67(3):304-9.

31. Reyburn H, Mbatia R, Drakeley C, Carneiro I, Mwakasungula E, Mwerinde O, et al. Overdiagnosis of malaria in patients with severe febrile illness in Tanzania: a prospective study. BMJ. 2004;329(7476):1212.

32. De Beaudrap P, Etard JF, Diouf A, Ndiaye I, Ndeye GF, Sow PS, et al. Incidence and determinants of new AIDS-defining illnesses after HAART initiation in a Senegalese cohort. BMC Infect Dis. 2010;10:179.

33. de Cherif TK, Schoeman JH, Cleary S, Meintjes GA, Rebe K, Maartens G. Early severe morbidity and resource utilization in South African adults on antiretroviral therapy. BMC Infect Dis. 2009;9:205.

34. Anglaret X, Minga A, Gabillard D, Ouassa T, Messou E, Morris B, et al. AIDS and non-AIDS morbidity and mortality across the spectrum of CD4 cell counts in HIV-infected adults before starting antiretroviral therapy in Cote d'Ivoire. Clin Infect Dis. 2012;54(5):714-23.
35. Curtis AJ, Marshall CS, Spelman T, Greig J, Elliot JH, Shanks L, et al. Incidence of WHO stage 3 and 4 conditions following initiation of anti-retroviral therapy in resource limited settings. PLoS One. 2012;7(12):e52019.

36. World Health Organization. Investing in Health for Africa. The Case for Strengthening Systems for Better Health Outcomes. Geneva; 2011. Available at: http://www.who.int/pmnch/media/membernews/2011/ investing_health_africa_eng.pdf?ua=1. Accessed October, 15, 2014.

37. Beauliere A, Toure S, Alexandre PK, Kone K, Pouhe A, Kouadio B, et al. The financial burden of morbidity in HIV-infected adults on antiretroviral therapy in Cote d'Ivoire. PLoS One. 2010;5(6):e11213.

38. Boyer S, Marcellin F, Ongolo-Zogo P, Abega SC, Nantchouang R, Spire B, et al. Financial barriers to HIV treatment in Yaounde, Cameroon: first results of a national cross-sectional survey. Bull World Health Organ. 2009:87(4):279-87.

39. Dussault G, Fournier P, Letourmy A, editors. L'assurance maladie en Afrique francophone: améliorer l'accès aux soins et lutter contre la pauvreté. Washington, DC: The World Bank; 2006.

40. Munderi $P$, Grosskurth H, Droti B, Ross DA. What are the essential components of HIV treatment and care services in low and middle-income countries: an overview by settings and levels of the health system? AIDS. 2012;26 Suppl 2: S97-103.

41. Ross DA, South A, Weller I, Hakim J. HIV treatment and care systems: the way forward. AIDS. 2012;26 Suppl 2:S147-52.

42. UNAIDS. UNAIDS World AIDS Day Report 2012. Geneva; 2012. Available at: http://www.unaids.org/en/media/unaids/contentassets/documents/ epidemiology/2012/gr2012/JC2434_WorldAIDSday_results_en.pdf. Accessed December 10, 2014.

43. World Health Organization. WHO consultation on technical and operational recommendations for scale-up of laboratory services and monitoring HIV antiretroviral therapy in resource-limited settings; 2004. Available at: http:// www.who.int/diagnostics_laboratory/LabMeetingDec_2004.PDF?ua=1. Accessed January 20, 2015.

\section{Submit your next manuscript to BioMed Central and take full advantage of:}

- Convenient online submission

- Thorough peer review

- No space constraints or color figure charges

- Immediate publication on acceptance

- Inclusion in PubMed, CAS, Scopus and Google Scholar

- Research which is freely available for redistribution 